\title{
MAPEAMENTO DA PRODUÇÃO CIENTÍFICA EM EDUCAÇÃO MATEMÁTICA QUE TRATA DE MATERIAIS CURRICULARES EDUCATIVOS
}

\author{
Reinaldo Feio Lima \\ Doutor em Educação, Universidade Federal do Sul e Sudeste do Pará, Brasil \\ reinaldo.lima@unifesspa.edu.br
}

\begin{abstract}
Resumo
O presente artigo é um breve recorte da tese de doutorado defendida no Programa de Pós-Graduação em Educação, da Universidade Federal da Bahia - UFBA, intitulada "Mensagem pedagógica em textos de Materiais Curriculares Educativos". Este estudo tem por objetivo mostrar um mapeamento da produção científica em Educação Matemática, a partir de teses e dissertações que contemplam pesquisas relacionadas a Materiais Curriculares Educativos, apresentadas no período 2013-2018 em programas de pós-graduação existentes no Brasil. O mapeamento foi realizado na Biblioteca Digital Brasileira de Teses e Dissertações - BDTD, considerando as palavras-chave "materiais curriculares" e "materiais curriculares educativos". Nesta, foram identificadas 06 teses e 06 dissertações. O artigo traz contribuições significativas para compreender os avanços desse campo emergente de pesquisa, destacando a diversidade teórica e metodológica de investigação, os focos temáticos, bem como as lacunas ainda a serem investigadas. Ademais, aponta a necessidade de futuras pesquisas que apresentem novas descobertas e possibilidades para a formação de professores que ensinam Matemática.
\end{abstract}

Palavras-chave: Materiais curriculares educativos, Mapeamento, BDTD.

\section{MAPPING OF THE SCIENTIFIC PRODUCTION IN MATHEMATICAL EDUCATION THAT DEALS WITH EDUCATIONAL CURRICULAR MATERIALS}

\begin{abstract}
This article is a brief clipping of the doctoral thesis defended in the Post-Graduation Program in Education, of the University Federal of Bahia - UFBA, entitled "Pedagogical message in texts of Educational Curricular Materials". This study intends to show a mapping of the scientific production in Mathematical Education based on thesis and dissertations which include researches referring to the Educational Curricular Materials presented in the period of 2013-2018 in programs of post-graduation that exists in Brazil. The mapping occurred in the Brazilian Digital Library of Thesis and Dissertations - BDLTD, considering the keywords "curricular materials" and "educational curricular materials". In this, 06 thesis and 06 dissertations were identified. The article brings significant contributions in order to understand the advances of this emergent field of research, highlighting the methodological and theoretical diversity of investigation, the thematic focuses as well the gaps that still will be investigated. Moreover, it points to the necessity of future researches which present new discoveries and possibilities for teachers training who teach Mathematic.
\end{abstract}

Keywords: Educational Curricular Materials, Mapping, BDTD.

Revista de investigação e divulgação em Educação Matemática, Juiz de Fora, v. 3, n. 2, p. 5-21, jul./dez. 2019. 


\section{Considerações iniciais}

Esta pesquisa tem como objetivo mostrar um mapeamento da produção científica em Educação Matemática, a partir de teses e dissertações que contemplam pesquisas relacionadas a Materiais Curriculares Educativos, apresentadas no período 2013-2018 em programas de pós-graduação existentes no Brasil. Esse estudo foi impulsionado pelo início da escrita da tese de doutorado do primeiro autor deste artigo, no Programa de Pós-Graduação em Educação da Universidade Federal da Bahia.

Atrelado a isso, buscamos conhecer as contribuições do que já vem sendo feito na área e quais os caminhos trilhados pelas pesquisas, as instituições nas quais estão concentradas e suas datas de publicação, a fim de ter um panorama das produções científicas em Educação Matemática bem como as lacunas a serem investigadas, identificar quais tendências temáticas foram privilegiadas nesses estudos e ampliando nosso olhar sob esse foco. Acreditamos que conhecer e estudar as obras e investigações recentes no campo de Materiais Curriculares Educativos é fundamental para o pesquisador que visa contribuir de forma significativa para o fortalecimento do campo de estudos em que se situa.

Salientamos que ao denominarmos "pesquisa científica em Educação Matemática" estamos considerando as produções das duas áreas da Capes: Educação (Área 38) e Ensino (Área 46), envolvendo os cursos de mestrado profissional, mestrado acadêmico e doutorado, cobrindo um período que vai de 2013 a 2018. Portanto, concordamos com Teixeira e Megid Neto (2017) quando afirmam que as dissertações e teses produzidas nos programas de pósgraduação nas instituições de ensino no país podem não representar toda a produção científica em Educação Matemática, mas esses textos produzidos no âmbito dos cursos de mestrado e doutorado configuram uma relação entre pesquisadores e os seus orientandos, constituindo-se num espaço imprescindível de formação de futuros pesquisadores para atuarem nas mais diversas instituições de todo país.

Do ponto de vista metodológico, assumimos no artigo uma perspectiva em consonância com pesquisas denominadas de Estado do Conhecimento (MOROSINI, 2015), para investigar a produção sobre Materiais Curriculares Educativos. Este mapeamento foi realizado a partir das produções disponibilizadas na Biblioteca Digital Brasileira de Teses e Dissertações - BDTD, que possuam como descritores "Material Curricular" e "Material Curricular Educativo" no título da tese ou dissertação. Justificamos nossa escolha por essa biblioteca, pois o acervo apresenta os textos completos de dissertações e teses, defendidas em 
instituições brasileiras. Esta biblioteca, lançada oficialmente em 2002, é mantida pelo Instituto Brasileiro de Informação em Ciência e Tecnologia - IBICT, no âmbito do Programa da Biblioteca Digital Brasileira - BDB, com apoio da Financiadora de Estudos e Pesquisas FINEP.

Em síntese, compreendemos o mapeamento da produção científica em Educação Matemática como um processo sistemático de levantamento e descrição de informações acerca das pesquisas produzidas sobre um campo específico de estudo, dentro de um determinado espaço (lugar) e período de tempo. Tais informações podem estar direcionadas aos aspectos físicos dessa produção (por exemplo, onde, quando e quantos estudos foram produzidos ao longo do período pré-determinado), bem como aos seus aspectos teóricometodológicos e temáticos (FIORENTINI; PASSOS; LIMA, 2016).

Cabe aqui salientar o conceito de Materiais Curriculares Educativos adotado nesse trabalho para fins de análise e discussão dos resultados. A expressão Materiais Curriculares Educativos é usada por nós em referencia a qualquer material físico ou digital que tem por objetivo apoiar a aprendizagem de professores, assim como a aprendizagem de estudantes (DAVIS; JANSSEN; DRIEL, 2017; REMILLARD; KIM, 2017). O adjetivo "educativo" refere-se aos professores como aprendizes (McNEILL et al., 2017). Já a expressão "aprendizagem" foi empregada no sentido de gerar possíveis mudanças nos padrões de produção de textos de professores e estudantes em contato com esses materiais (CHOPPIN, 2011).

A exclusão, neste momento, de outros tipos de informações (por exemplo, artigos, anais de eventos) que têm o material curricular educativo como foco de estudo, deve-se, primeiramente, à necessidade de revisão sistemática da produção científica em Educação Matemática em dissertações e teses. Segundo, da nossa necessidade de conhecer o que está sendo pesquisado na comunidade acadêmica. As dissertações e teses foram analisadas com relação aos seguintes critérios: instituição, programa, área, título, ano de apresentação, grau de titulação acadêmica, conteúdo matemático, escolaridade, foco temático do estudo. E, como critério de inclusão, somente as pesquisas que tivessem no título do trabalho os descritores: "Material Curricular" e "Materiais Curriculares Educativos".

Refletindo sobre a necessidade de um olhar sobre estas produções científicas em Educação Matemática no contexto dos Materiais Curriculares Educativos, surge a ideia de produção deste trabalho, com a intenção de responder a uma pergunta básica: $O$ que revelam 
as produções cientificas sobre Materiais Curriculares Educativos nas pesquisas em Educação Matemática?

Com essas considerações iniciais evidenciamos o contexto da produção deste artigo. Na próxima seção, apresentamos os procedimentos metodológicos traçados na pesquisa que possibilitaram a obtenção do corpus, bem como alguns achados que o recorte investigativo oportunizou. Ressalta-se que foram efetuadas investigações de dissertações e teses que apresentavam estudos sobre Materiais Curriculares Educativos.

\section{A constituição do corpus e os procedimentos de análise}

Os procedimentos adotados neste estudo são de caráter qualitativo exploratório (MARCONI; LAKATOS, 2009) do tipo de estudo bibliográfico com características de mapeamento de pesquisa, pois o objetivo é "priorizar os aspectos descritivos de um campo de pesquisa em detrimento dos resultados, embora estes também possam ser mapeados" (FIORENTINI; PASSOS; LIMA, 2016, p. 7).

Compreendemos a pesquisa bibliográfica como um procedimento metodológico utilizado na busca de soluções para um problema de pesquisa. Barbosa (2017) salienta que nessa abordagem, a análise se dá por meio de materiais que já receberam alguma abordagem analítica ou problematizadora reconhecida como pertencente ao campo científico, para isso, é necessário expor a maneira como ocorreu a construção do desenho metodológico e a escolha pelos procedimentos utilizados (LIMA; MIOTO, 2007).

Para a análise do corpus, realizamos um estado do conhecimento que constitui numa importante fonte para a produção científica em Educação Matemática, não só por acompanhar todo o processo monográfico, mas prioritariamente, por contribuir para a ruptura com os préconceitos que o pesquisador porta ao iniciar o seu estudo (MOROSINI, 2015). Por meio dessa abordagem, destacam-se os resultados das pesquisas e executa-se uma análise das dissertações e teses produzidas no campo em estudo (FIORENTINI et al, 2016).

Dessa forma, ressalta-se que o mapeamento realizado perfaz uma característica descritiva de uma determinada área de pesquisa, no caso aqui, Educação Matemática, explicitando quais estudos foram produzidos, quando e onde aconteceram; revelando aspectos teórico-metodológicos e os temas das pesquisas realizadas que tratam de Materiais Curriculares Educativos (FIORENTINI et al, 2016). Elaborar um mapeamento da produção científica em Educação Matemática significa fazer "uma síntese integrativa da produção acadêmica em uma determinada área do conhecimento e em um período estabelecido de 
tempo" (ANDRÉ, 2009, p. 43). Assim, para este artigo, tem como corpus as teses e dissertações disponibilizada na BDTD e que tratam de Materiais Curriculares Educativos, além da busca em dados do portal de Teses e Dissertações da Coordenação de Aperfeiçoamento de Pessoal de Nível (CAPES).

O recorte temporal dado à esta investigação ocorreu no período de janeiro de 2013 a dezembro de 2018 e centrou-se no mapeamento enquanto "possibilidade de se compreender um fenômeno, um fato para que, então, sejam descobertos caminhos ou formas para mudar, melhorar, prever ou criar algo relativo ao fenômeno ou fato em questão" (BIEMBENGUT, 2008, p. 71). O recorte temporal justifica-se pelo interesse em conhecer as investigações mais recentes na área. Para Morosini (2015) o mapeamento das produções científicas mais recentes na área é fundamental para o pesquisador interessado em justificar suas escolhas de pesquisa, pois lhe fornece indícios acerca dos interesses de pesquisa mais desenvolvidos, como também sobre possíveis lacunas a serem pesquisadas sobre o tema em estudo.

Após a leitura dos resumos, o corpus da pesquisa ficou constituído por 12 trabalhos relacionados a temática. Dos trabalhos escolhidos, a análise dessa produção foi realizada a partir de duas etapas: a primeira etapa da análise envolveu a de releitura seus resumos, de forma minuciosa e, quando necessário, realizamos a leitura do próprio texto, na busca de mais detalhes para nossa interpretação, já que os resumos permitem contar uma história de determinada produção acadêmica, já que outras são possíveis (GARNICA, 2013). E, segundo, da organização dos dados em planilhas, tabelas e quadros, procurando facilitar a apresentação e discussão dos dados. Apresentamos a seguir, nossas impressões e a sistematização de nosso olhar a partir do corpus, haja vista que não têm a intenção de generalizar os resultados para outros indivíduos, locais ou situações além daqueles que foram estudados (CRESWELL, 2010). Inicialmente, o quadro 1 listamos os 12 trabalhos analisados.

Quadro 1 - Códigos e referências dos trabalhos analisados

\begin{tabular}{|c|c|c|c|}
\hline Código & Referência & Código & Referência \\
\hline MA01 & Silva (2013) & TD01 & Souza (2015) \\
\hline MA02 & Aguiar (2014) & TD02 & Santana (2015) \\
\hline MA03 & Prado (2014) & TD03 & Januário (2017) \\
\hline MA04 & Pacheco (2015) & TD04 & Santana (2017) \\
\hline MA05 & Costa (2015) & TD05 & Bueno (2017) \\
\hline MP01 & Lima (2014) & TD06 & Diniz (2017) \\
\hline
\end{tabular}

Revista de investigação e divulgação em Educação Matemática, Juiz de Fora, v. 3, n. 2, p. 5-21, jul./dez. 2019. 
Fonte: Elaborado pelo autor com base em Teixeira e Cyrino (2013).

Atribuímos a nomenclatura "MA" para designar dissertação de mestrado acadêmico, seguida de um número que representa a ordem cronológica em que foi publicada. Do mesmo modo foi atribuída para dissertação de mestrado profissional (MP) e tese de doutorado (TD). Descreve-se, a seguir, a identificação, interpretação e discussão dos dados levantados.

\section{Apresentação e discussão dos dados}

Foram mapeadas 12 (doze) dissertações e teses defendidas em 3 (três) programa de pós-graduação sediados a duas instituições de ensino, nomeadamente: Universidade Federal da Bahia (UFBA) e Pontifícia Universidade Católica de São Paulo. Portanto, os trabalhos compreendem pesquisa de mestrado acadêmico, mestrado profissional e doutorado.

Tabela 1 - Dissertações e Teses defendidas no período de 2013 a 2018

\begin{tabular}{|c|l|c|c|c|c|}
\hline \multicolumn{6}{|c|}{ Números de textos - Dissertações e Teses defendidas no período de 2013 a 2018} \\
\hline INSTITUIÇÃO & \multicolumn{1}{|c|}{ PROGRAMA } & ÁREA & MP & MA & DO \\
\hline UFBA & $\begin{array}{l}\text { Programa de Pós-Graduação Ensino, } \\
\text { Filosofia e História das Ciências }\end{array}$ & Ensino & 0 & 3 & 2 \\
\hline UFBA & Programa de Pós-Graduação em Educação & Educação & 0 & 1 & 1 \\
\hline PUC/SP & $\begin{array}{l}\text { Programa de Pós-Graduação em Educação } \\
\text { Matemática }\end{array}$ & Ensino & 1 & 1 & 3 \\
\hline TOTAL & & & 1 & 5 & 6 \\
\hline
\end{tabular}

Fonte: Elaborado pelo autor.

A Universidade Federal da Bahia - UFBA oferece dois programas de pós-graduação, um da área da Educação e outro da área de Ensino. O programa de Pós-Graduação em Educação, começou seu mestrado acadêmico em 1971 e o Doutorado em 1992 e, atualmente, possui cinco linhas de pesquisas: (1) Currículo e (In)formação; (2) Linguagens, Subjetivações e Práxis Pedagógica; (3) Política e Gestão da Educação; (4) Educação, Cultura Corporal e Lazer; (5) Educação e Diversidade. Já o Programa de Pós-Graduação em Ensino, Filosofia e 
História das Ciências teve seu início com o curso de mestrado acadêmico em 2000 e o Doutorado em 2006. Esse programa resulta de uma associação da Universidade Federal da Bahia (UFBA) e à Universidade Estadual de Feira de Santana (UEFS) por meio de convênio entre as duas universidades. Se organiza em três linha de pesquisa: (1) Ensino de Ciências; (2) História das Ciências e (3) Filosofia das Ciências.

O Programa de Pós-Graduação em Educação Matemática da Pontifícia Universidade Católica de São Paulo - PUC/SP, vinculado à área de Ensino na CAPES, abriu o curso de mestrado acadêmico em 1975, sendo que 1997 o curso de Mestrado Acadêmico foi credenciado pela CAPES, em 2002 aprovação pela CAPES do mestrado profissional em Ensino de Matemática e doutorado em Educação Matemática. Apresenta três linhas de pesquisa: (1) A Matemática na Estrutura Curricular e Formação de Professores; (2) História, Epistemologia e Didática da Matemática e; (3) Tecnologias da informação e Educação Matemática.

Considerando os dados disponíveis na tabela 1, é inevitável constatar que as instituições públicas continuam a constituir o ambiente para formação de professores que ensinam matemática e produção de conhecimento que tratam de Materiais Curriculares Educativos. Quanto às áreas de conhecimento dos programas de pós-graduação responsáveis pela produção científica em Educação Matemática aqui analisadas, temos as seguintes informações.

O mapeamento detectou 12 textos em duas Instituições de Ensino Superior (IES). O programa de Pós-Graduação em Educação e o Programa de Pós-Graduação Ensino, Filosofia e História das Ciências, ambos sediados na Universidade Federal da Bahia (UFBA), são responsáveis por 58,33\% (7 textos), o que corresponde a quatro dissertações de mestrado e três teses de doutorado. Enquanto, o Programa de Pós-Graduação em Educação Matemática sediada na Pontifícia Universidade Católica de São Paulo (PUCSP), instituição privada, concentrando $41,67 \%$ (5 textos) de toda a produção mapeada até 2018 , totalizando duas dissertações de mestrado (uma a nível de mestrado profissional e outra acadêmica) e três teses de doutorado.

Outra característica marcante nesse mapeamento, diz respeito aos mestrados profissionais. Os dados sugerem que há poucas produções sobre os MP, tanto para o campo de pesquisa, quanto para a qualidade da formação de professores que ensinam matemática e dos processos de ensino e aprendizagem na área. Inferimos, portanto, da necessidade de realizarmos estudos mais aprofundados sobre Materiais Curriculares Educativos, na tentativa 
de acumularmos dados empíricos para abastecer as reflexões sobre esse fenômeno dentro da área da Educação Matemática. Logo, o “interessante será acompanhar os reflexos desse movimento nos próximos anos, assim como o impacto dos trabalhos realizados nesses cursos em termos de geração de conhecimento e de formação docente" (TEIXEIRA; MAGID NETO, 2017, p.528).

Vale observar, ainda, cruzando os dados do Quadro 1 e Tabela 1, a crescente produção de dissertações de mestrado acadêmico ao longo de todo o período mapeado. As teses de doutorado publicadas são evidenciadas somente nos anos de 2015 e 2017. De todo modo, as teses de doutorado correspondem a $50 \%$ da produção analisada. A dissertação de mestrado profissional aparece somente no ano de 2014. Na esteira desse processo, na área de Ensino (CAPES) ${ }^{1}$, até novembro de 2018 encontrávamos 204 cursos de pós-graduação: 79 cursos de mestrado acadêmico, 36 de doutorado e 89 de mestrado profissional. Com efeito, atualmente a maioria dos cursos da referida área é constituída de MP (43,63\%). Quando olhamos para área de Educação, por meio da consulta realizada no site da CAPES, 46 (18,25\%) cursos de mestrado profissional, 130 de mestrado acadêmico e 76 cursos de doutorado.

A tabela 2, que se segue, traz um panorama geral dos critérios utilizados para capturar as informações presentes em cada dissertação e teses mapeadas.

Tabela 2 - Quantidades de textos que explicitam abordagem teórica, metodológica, coleta dos dados e foco temático.

\begin{tabular}{|c|c|c|c|c|c|}
\hline Código & $\begin{array}{l}\text { Ano de } \\
\text { defesa }\end{array}$ & $\begin{array}{c}\text { Abordagem } \\
\text { teórica }\end{array}$ & $\begin{array}{l}\text { Abordagem } \\
\text { metodológica }\end{array}$ & $\begin{array}{c}\text { Coleta dos } \\
\text { dados }\end{array}$ & $\begin{array}{c}\text { Foco } \\
\text { Temático }\end{array}$ \\
\hline MA01 & 2013 & $\begin{array}{c}\text { Teoria de Basil } \\
\text { Bernstein }\end{array}$ & Qualitativa & $\begin{array}{c}\text { Observação } \\
\text { Entrevista } \\
\text { análise } \\
\text { documental }\end{array}$ & $\begin{array}{l}\text { Formação } \\
\text { Inicial }\end{array}$ \\
\hline MA02 & 2014 & $\begin{array}{c}\text { Teoria de Basil } \\
\text { Bernstein }\end{array}$ & Qualitativa & $\begin{array}{c}\text { Observação } \\
\text { Entrevista } \\
\text { análise } \\
\text { documental }\end{array}$ & $\begin{array}{l}\text { Formação } \\
\text { Inicial }\end{array}$ \\
\hline MA03 & 2014 & $\begin{array}{c}\text { Teoria de Basil } \\
\text { Bernstein }\end{array}$ & Qualitativa & $\begin{array}{c}\text { Análise } \\
\text { documental }\end{array}$ & $\begin{array}{c}\text { Prática } \\
\text { Pedagógica }\end{array}$ \\
\hline MA04 & 2015 & Estudos de Brown & Qualitativa & $\begin{array}{c}\text { Observação } \\
\text { Entrevista } \\
\text { análise } \\
\text { documental }\end{array}$ & $\begin{array}{l}\text { Formação } \\
\text { Inicial }\end{array}$ \\
\hline MA05 & 2015 & Estudos Jean Lave & Qualitativa & Observação & Formação \\
\hline
\end{tabular}

${ }^{1}$ Dados obtidos em visita à página da CAPES. Recuperado de http://www.capes.gov.br/cursosrecomendados. Acesso: novembro 2018.

Revista de investigação e divulgação em Educação Matemática, Juiz de Fora, v. 3, n. 2, p. 5-21, jul./dez. 2019. 


\begin{tabular}{|c|c|c|c|c|c|}
\hline & & e Etienne Wenger & & $\begin{array}{l}\text { Entrevista } \\
\text { análise } \\
\text { documental }\end{array}$ & Continuada \\
\hline MP01 & 2014 & Estudos de Brown & Qualitativa & $\begin{array}{c}\text { Questionário } \\
\text { áudio } \\
\text { gravação }\end{array}$ & $\begin{array}{l}\text { Formação } \\
\text { Inicial }\end{array}$ \\
\hline TD01 & 2015 & $\begin{array}{l}\text { Estudos de Jean } \\
\text { Lave e Etienne } \\
\text { Wenger }\end{array}$ & Qualitativa & $\begin{array}{c}\text { Observação } \\
\text { entrevista }\end{array}$ & $\begin{array}{l}\text { Formação } \\
\text { Continuada }\end{array}$ \\
\hline TD02 & 2015 & $\begin{array}{l}\text { Teoria de Basil } \\
\text { Bernstein }\end{array}$ & Qualitativa & $\begin{array}{l}\text { Observação } \\
\text { Entrevista } \\
\text { análise } \\
\text { documental }\end{array}$ & $\begin{array}{l}\text { Formação } \\
\text { Inicial }\end{array}$ \\
\hline TD03 & 2017 & $\begin{array}{l}\text { Estudos Saupe e } \\
\text { Alves e Brown }\end{array}$ & Qualitativa & $\begin{array}{c}\text { Análise } \\
\text { documental }\end{array}$ & $\begin{array}{l}\text { Formação } \\
\text { Continuada }\end{array}$ \\
\hline TD04 & 2017 & Estudos de Brown & Qualitativa & $\begin{array}{l}\text { Relatório de } \\
\text { pesquisa }\end{array}$ & $\begin{array}{l}\text { Formação } \\
\text { Continuada }\end{array}$ \\
\hline TD05 & 2017 & Estudos de Brown & Qualitativa & $\begin{array}{l}\text { Trabalho de } \\
\text { campo } \\
\text { Observação } \\
\text { análise } \\
\text { documental } \\
\end{array}$ & $\begin{array}{l}\text { Formação } \\
\text { Continuada }\end{array}$ \\
\hline TD06 & 2017 & $\begin{array}{c}\text { Teoria de Basil } \\
\text { Bernstein }\end{array}$ & Qualitativa & $\begin{array}{l}\text { Observação } \\
\text { Entrevista } \\
\text { análise } \\
\text { documental }\end{array}$ & $\begin{array}{l}\text { Formação } \\
\text { Continuada }\end{array}$ \\
\hline
\end{tabular}

Fonte: Elaborado pelo autor.

Entre as pesquisas catalogadas, há prevalência de trabalhos pautados metodologicamente pelo método qualitativo de investigação em Educação Matemática. Há predomínio dos estudos empírico-descritivos (68\%), sobretudo aqueles centrados na utilização de múltiplos instrumentos de coleta de dados para a compreensão do fenômeno. Como exemplo, podemos citar o uso observações, entrevistas, análise documental, questionários, relatório de pesquisa, etc. Inspirados nos estudos de Teixeira e Magid Neto (2017), estamos considerando os estudos empírico-descritivos caracterizado pela realização de pesquisa, com a efetiva coleta de dados, voltada para identificar, diagnosticar, descrever, caracterizar a existência de um fenômeno, buscando formas para explicar os fenômenos examinados.

No processo de releituras dos resumos para efetuar o fichamento, o descritor "foco temático" nos chamou atenção. Isto é, a formação de professores predomina nas pesquisas. No presente artigo, estaremos considerando a formação inicial e a continuada sempre que nos 
referimos à formação de professores (CYRINO; OLIVEIRA, 2016). O número expressivo de textos integrantes a este descritor, evidencia a relevância da continuidade de investimento em pesquisas na/para formação de professores, no cenário nacional, na área da Educação Matemática. Apresentamos a seguir alguns aspectos que julgamos relevantes.

Assim como MA01 (SILVA, 2013), a pesquisa de MA02 (AGUIAR, 2014), MA03 (PRADO, 2014), TD02 (SANTANA, 2017) e TD06 (DINIZ, 2017) centra seus referenciais teóricos na Teoria de Basil Bernstein. Entre os trabalhos, Silva (2013), buscou compreender como professores operam a recontextualização pedagógica de materiais curriculares educativos sobre modelagem matemática. Os dados referentes à pesquisa qualitativa foram produzidos por meio da observação, entrevistas e analise de documentos. Como resultado, os dados analisados apontaram cinco princípios que orientaram os professores na recontextualização dos materiais curriculares educativos sobre modelagem matemática para as práticas pedagógicas: discussão/reflexão sobre o tema; conteúdo da grade curricular; estrutura do material curricular; relação entre sujeitos na prática pedagógica e investigação da situação-problema, e cinco estratégias adotadas pelos professores no processo de recontextualização dos materiais curriculares educativos sobre modelagem matemática: estratégias para convidar estudantes no momento inicial do ambiente de modelagem; estratégias para estudantes realizarem o que foi solicitado na tarefa; estratégias para estudantes prosseguirem à resolução da tarefa; estratégias para atender ao tempo previsto e cumprir o programa da grade curricular; e estratégias para enquadrar o programa no ambiente de modelagem.

Semelhante a esta pesquisa, Aguiar (2014) investigou como professores operam a recontextualização de textos dos materiais curriculares educativos nas práticas pedagógicas e quais princípios regulam a operacionalização da recontextualização. Os dados referentes à pesquisa qualitativa foram produzidos por meio da observação, entrevistas e análise de documentos. Os resultados mostraram que a tarefa matemática contida no material curricular educativo nem sempre é implementada de acordo com a intenção inicial dos seus elaboradores, ou seja, os professores operam a recontextualização dos textos dos materiais curriculares educativos para atender a princípios presentes na prática pedagógica. Esses princípios foram identificados e nomeados como: Princípio das questões que afetam o cotidiano dos estudantes, Princípio dos conteúdos disciplinares prescritos e Princípio da ausência de experiência do estudante com tarefas investigativas. 
Em outra pesquisa, Prado (2014) investigou as imagens da prática pedagógica em materiais curriculares educativos sobre modelagem matemática. Foi utilizado o método qualitativo e os dados foram produzidos por meio da análise documental. Seus resultados apontaram duas imagens: uma imagem de deslocamentos caracterizada pela intensa variação entre um enquadramento muito forte, no qual as práticas pedagógicas se aproximam da zona de conforto e valores mais fracos de enquadramentos, nos quais a prática pedagógica pode ser descrita por uma aproximação da zona de risco. Em outra imagem flexibilizadora, a qual pode ser entendida como aquela que cria, condiciona e organiza as possibilidades para o esbatimento do grau de isolamento nas relações discursivas (relações entre discursos) assim como nas relações espaciais (relações entre espaços).

As pesquisas de Silva (2013), Aguiar (2014) e Prado (2014) percebe-se que há certa convergência entre todos os autores no aspecto relacionado a partir do interesse dos autores na utilização da Teoria de Basil Bernstein ${ }^{2}$ para analisar o material curricular educativo sobre modelagem matemática. As três pesquisas consideram que os materiais curriculares educativos como mais um apoio a prática pedagógica a qual o professor participa.

Com ênfase na perspectiva teórica de Lave e Wenger (1991) e Wenger (1998). Costa (2015) analisou como professores de matemática participam da elaboração de tarefas matemáticas que constituem um material curricular educativo em um trabalho colaborativo. Considerou os procedimentos metodológicos do método qualitativo, na qual utilizamos como artifícios de coleta de dados a observação e as entrevistas estimuladas para as análises referentes à participação dos professores, e análise documental das tarefas matemáticas que constituem um material curricular educativo elaboradas pelos professores durante o trabalho colaborativo. Os resultados apontaram que a participação dos professores na elaboração de tarefas matemáticas ocorre de três formas distintas: contemplando objetivos comuns do grupo, compartilhando sobre modos de elaborar questões matemáticas investigativas ou exploratórias e produzindo tarefas na perspectiva das práticas que participam outros professores de matemática.

Souza (2015) em pesquisa realizada com professores de Matemática da rede municipal de Salvador ao utilizar materiais curriculares educativos em suas práticas pedagógicas da qual

\footnotetext{
${ }^{2}$ Basil Bernstein, sociólogo da educação britânica, é um autor cuja obra está centrada nas relações entre linguagem e educação e, de acordo com ele, seria um papel da sociologia da educação "explicar as formas como as instituições educacionais expressam características da sociedade da qual fazem parte" (SANTOS, 2003, p. 21). Enquanto sociólogo crítico do processo de escolarização, Bernstein inclui a pedagogia, o currículo e a avaliação como formas de controle social (MAINARDES; STREMEL, 2010).
}

Revista de investigação e divulgação em Educação Matemática, Juiz de Fora, v. 3, n. 2, p. 5-21, jul./dez. 2019. 
participa, bem como apontar possíveis indícios das oportunidades de aprendizagens docentes ao fazer uso na sala de aula. Para isso, a observação e a entrevista foram utilizadas como procedimentos de coleta de dados. De modo geral, os resultados apontaram que o docente pode participar das aulas seguindo as sugestões e exemplos do material, podendo diversificar nas estratégias de ensino ou ainda, usar o material como acessório na sala de aula.

Do mesmo modo, os resultados da pesquisa Lima (2014) constataram que os professores que participaram de sua pesquisa, se relacionavam com os materiais curriculares educativos, ora reproduzindo, ora adaptando. Do mesmo modo, Pacheco (2015) e Bueno (2017), esses autores observaram que as professoras, participantes da pesquisa, usavam de diferentes modos os materiais curriculares educativos em uma mesma aula - reprodução, adaptação e improvisação. Esses modos de uso podem estar relacionados a alguns fatores elencados pelas autoras, por exemplo, formação, participação em cursos de pós-graduação, confiança no conteúdo, o conhecimento pedagógico do conteúdo.

As pesquisas de Januário (2017) e Santana (2017) convergiram para o mesmo foco, ou seja, debruçaram suas análises sobre o relatório de um projeto de pesquisa em que professores da rede municipal de ensino de São Paulo avaliaram os materiais curriculares por eles utilizados para planejar e desenvolver suas aulas. Como resultados, os pesquisadores indicaram que a relação professor-material curricular educativo caracteriza uma "via de mão dupla": os professores mobilizam seus conhecimentos para interpretar, compreender e colaborar com os recursos curriculares educativos, reconciliam suas percepções dos objetivos originais dos materiais com seus próprios objetivos e tomam decisões quanto ao uso, seja por reprodução, adaptação ou improvisação da tarefa matemática contida no material curricular educativo.

Diante dos trabalhos apresentados podemos destacar a relevância atribuída pelos pesquisadores para o Material Curricular Educativo, em nível do uso (BUENOS, 2017; PACHECO, 2017), assim como a relação (LIMA, 2014; JANUÁRIO, 2017; SANTANA, 2017). Participação e aprendizagem também foram discutidas, entre estas, a pesquisa de (COSTA, 2015; SOUZA, 2015) e fazendo uso dos construtos teóricos da Teoria De Basil Bernstein (SILVA, 2013; AGUIAR, 2014; PRADO, 2014; SANTNA, 2015; DINIZ, 2017).

A constatação é de que temos em curso o fortalecimento de concepções teóricas e metodológicas que possam a orientar os estudos e as pesquisas no campo da Educação Matemática que tratam de Materiais Curriculares Educativos o que rearma a nossa aposta: a consolidação desse campo emergente de pesquisa e intervenção na sala de aula. 


\section{Considerações finais}

Ao finalizar este estudo que teve como objetivo mostrar um mapeamento da produção científica em Educação Matemática, a partir de teses e dissertações que contemplam pesquisas relacionadas a Materiais Curriculares Educativos, apresentadas no período 20132018 em programas de pós-graduação existentes no Brasil. Diante disso, explicitamos algumas considerações finais, fruto de discusões sobre o conjunto de informações apresentadas ao longo do presente artigo que acarreta possíveis resposta a nossa questão de pesquisa.

Mapear a produção científica em Educação Matemática, disponibilizadas na BDTD, possibilitou constatar 12 pesquisas, sendo 06 dissertações e 06 teses, publicadas entre 2013 a 2018, que trazem em seu bojo Materiais Curriculares Educativos. Alguns aspectos ficaram evidentes neste mapeamento: uma ascendência, com o passar do tempo, do número de trabalhos, com destaque para o período posterior a 2013; concentração da maior parte das pesquisas na UFBA e PUC/SP; e um predomínio dos estudos envolvendo a formação de professores que ensinam Matemática na Educação Básica.

Os trabalhos apresentados no período investigados estão voltados, principalmente, para o interesse em pesquisar aspectos atinentes a Formação de Professores que ensinam Matemática, bem como a relação e uso de professores-materiais curriculares educativos. Aspecto relevante, devido a este profissional ser o principal responsável pelo ensino e promoção da aprendizagem dos conceitos matemáticos na Educação Básica.

Essas pesquisas reforçam a ideia apresentada por Remillard e Kim (2017), que os elementos que constituem esses materiais podem apoiar a aprendizagem de professores que ensinam matemática. Conforme os estudos Boas e Barbosa (2016), que caracterizaram aprendizagens por professores de matemática ao utilizar materiais curriculares educativos em três oportunidades de aprendizagens, por exemplo: oportunidades de aprendizagens relacionadas à abordagem comunicativa na sala de aula, oportunidades de aprendizagens relacionadas aos cenários para investigação e oportunidades de aprendizagens relacionadas ao desenvolvimento profissional.

O mapeamento das teses e dissertações que tratam de Materiais Curriculares Educativos, aponta a necessidade da consolidação desse campo emergente de pesquisa. Ressalta- se que entre 2013 a 2018 foram produzidos um total de 12 trabalhos; porém, nesses 5 anos, a produção não ocorreu de maneira linear. As pesquisas existentes já deram conta de 
constatar o quanto os elementos que constituem esses materiais podem apoiar a aprendizagem de professores e estudantes. Com isso notamos a necessidade da realização de novas investigações voltadas para o Ensino Superior e Educação de Jovens e Adultos, lacuna observada nas análises do nosso corpus.

Destacamos que, este artigo teve caráter preliminar, apresentando algumas limitações, que poderão ser investigadas em pesquisas futuros. A primeira limitação relaciona-se ao número de dissertações e teses e de programas analisados. A segunda limitação relaciona-se a não identificação de artigos para este corpus, com referências sobre o tema em foco, fato que nos levou a analisar apenas teses e dissertações.

Em linhas conclusivas, o mapeamento aqui divulgado permite uma série de reflexões e inúmeras considerações, dependendo do foco de interesse do leitor. De qualquer forma, entendemos que a construção deste artigo contribui para o avanço de nossa compreensão sobre Materiais Curriculares Educativos. A discussão aqui apresentada contribui para a visualização de características do estado do conhecimento sobre o tema em foco, abrindo espaço para a realização de estudos analíticos concentrados em aspectos específicos relativos a produção inventariada, e, ainda, aos novos investigadores que se iniciam na pesquisa em Educação Matemática, por exemplo, qual a mensagem presente nesses materiais. Parafraseando o conhecido dramaturgo Samuel Beckett: “Tenta outra vez. Falha outra vez. Falha melhor".

\section{Referências}

ANDRÉ, M. A. A produção acadêmica sobre formação de professores: um estudo comparativo das dissertações e teses defendidas nos anos 1990 e 2000 . Formação Docente Revista Brasileira de Pesquisa sobre Formação Docente, v. 1, n. 1, p. 41-56, ago./dez. 2009.

BOAS, J. V.; BARBOSA, J. C. Aprendizagem do professor: uma leitura possível. Ciência e Educação (UNESP), v. 22, p. 1097-1107, 2016.

BIEMBENGUT, M. S. Mapeamento na pesquisa educacional. Rio de Janeiro: Ciência Moderna, 2008.

CHOPPIN, J. Learned adaptations: Teachers understanding and use of curriculum resources. Journal of Mathmatics Teacher Education, New York, v. 14, n. 5, p. 331-53, 2011.

CRESWELL, J. W. Projeto de pesquisa: métodos qualitativo, quantitativo e misto (3a ed.). Porto Alegre: Artmed, 2010.

Revista de investigação e divulgação em Educação Matemática, Juiz de Fora, v. 3, n. 2, p. 5-21, jul./dez. 2019. 
CYRINO, M. C. de C. T.; OLIVEIRA, H. M. Ensino exploratório e casos multimídia na formação de professores que ensinam matemática. In: Recurso multimídia para a formação de professores que ensinam matemática: elaboração e perspectivas / Márcia Cristina de Costa Trindade Cyrino (organizadora). - Londrina: Eduel, 2016.

FIORENTINI, D.; PASSOS, C. L. B.; LIMA, R. C. R. (Org.). Mapeamento da pesquisa acadêmica brasileira sobre o professor que ensina Matemática: período 2001 a 2012. Campinas: FE-Unicamp, 2016. v. 1.

GARNICA, A. V. M. História Oral e Educação Matemática. In: BORBA, M. C.; ARAÚJO, J. L. (Org.). Pesquisa Qualitativa em Educação Matemática. 5. ed. Belo Horizonte: Autêntica, 2013. p. 87-110.

JONEI, C. B. ABORDAGENS TEÓRICAS E METODOLÓGICAS NA EDUCAÇÃO MATEMÁTICA: APROXIMAÇÕES E DISTANCIAMENTOS. 38 ${ }^{\mathbf{a}}$ Reunião Nacional da ANPEd - 01 a 05 de outubro de 2017 - UFMA - São Luís/MA.

LIMA, T. C. S.; MIOTO, R. C. T. Procedimentos metodológicos na construção do conhecimento científico: a pesquisa bibliográfica. Katálysis, Florianópolis, v. 10, n. esp, p. 37-45, abr., 2007.

MAINARDES, J.; STREMEL, S. A teoria de Bsil Bernstein e algumas de suas contribuições para as pesquisas sobre políticas educacionais e curriculares. Teias, n. 22, v. 11, 2010.

MARCONI, M. A.; LAKATOS, E. M. Fundamentos de metodologia científica. $6^{\mathrm{a}}$ ed., $7^{\mathrm{a}}$ reimpressão. São Paulo: Atlas, 2009.

MOROSINI, M. C. Estado de conhecimento e questões do campo científico. Revista Educação, Santa Maria: UFSM, v. 40, n. 1, p. 101-116, jan./abr. 2015.

SANTOS, L. L. Bernstein e o campo educacional: relevância, influências e incompreensões. Cadernos de Pesquisas, São Paulo, n. 120, p. 15-49, 2003.

TEIXEIRA, B. R.; CYRINO, M. C. de C. T. O estágio supervisionado em cursos de licenciatura em Matemática: um panorama de pesquisas brasileiras. Educação Matemática Pesquisa, São Paulo, v. 15, n. 1, p. 29-49, 2013.

TEIXEIRA, P. M. M.; NETO, J. M. A Produção Acadêmica em Ensino de Biologia no Brasil - 40 anos (1972-2011): Base Institucional e Tendências Temáticas e Metodológicas.

RBPEC, v. 17, n.2, p. 521-549, 2017.

APÊNDICE - Relações das teses e dissertações do corpus de análise deste estudo

AGUIAR, Wagner Ribeiro. A transformação de textos de Materiais Curriculares Educativos por professores de Matemática nas práticas pedagógicas: uma abordagem sociológica com a lente teórica de Basil Berstein. 2014. 111f. Dissertação (Mestrado em Ensino, Filosofia e História das Ciências) - Universidade Estadual de Feira de Santana, Universidade Federal da Bahia. Salvador, 2014.

Revista de investigação e divulgação em Educação Matemática, Juiz de Fora, v. 3, n. 2, p. 5-21, jul./dez. 2019. 
BUENO, S. Uso de materiais curriculares por professores de Matemática. 2017. 168f. Tese (Doutorado em Educação Matemática) - Faculdade de Ciências Exatas e Tecnologia. Pontifícia Universidade Católica de São Paulo. São Paulo, 2017.

COSTA, W. O. A participação de professores de matemática e análise de materiais curriculares elaborados em um trabalho colaborativo. 2015. 111f. Dissertação (Mestrado em Ensino, Filosofia e História das Ciências) - Universidade Estadual de Feira de Santana, Universidade Federal da Bahia. Salvador, 2015.

DINIZ, P. Materiais curriculares educativos e professores que ensinam Matemática: mensagem, recontextualização e identidade Pedagógica. 2017. 139f. Tese (Doutorado em Ensino, Filosofia e História da Ciência) - Programa de Pós-Graduação em Ensino, Filosofia e História da Ciência. Universidade Federal da Bahia. Universidade Estadual de Feira de Santana. Salvador, 2017.

JANUÁRIO, G. Marco conceitual para estudar a relação entre materiais curriculares e professores de Matemática. 2017. 194f. Tese (Doutorado em Educação Matemática) Faculdade de Ciências Exatas e Tecnologia. Pontifícia Universidade Católica de São Paulo. São Paulo, 2017.

LIMA, S. F. Relações entre professores e materiais curriculares no ensino de números naturais e sistema de numeração decimal. 2014. 217f. Dissertação (Mestrado Profissional em Ensino de Matemática) - Faculdade de Ciências Exatas e Tecnologia. Pontifícia Universidade Católica de São Paulo. São Paulo, 2014.

PACHECO, D. R. O uso de materiais curriculares de Matemática por professores dos anos iniciais do Ensino Fundamental para o tema Espaço e Forma. 2015. 174f. Dissertação (Mestrado em Educação Matemática) - Faculdade de Ciências Exatas e Tecnologia. Pontifícia Universidade Católica de São Paulo. São Paulo, 2015.

PRADO, A. S. As imagens da prática pedagógica nos textos dos materiais curriculares educativos sobre modelagem matemática. 2014. 111f. Dissertação (Mestrado em Ensino, Filosofia e História da Ciência) - Programa de Pós-Graduação em Ensino, Filosofia e História da Ciência. Universidade Federal da Bahia. Universidade Estadual de Feira de Santana. Salvador, 2014.

SANTANA, K. C. L. Relação professor-materiais curriculares em Educação Matemática: uma análise a partir de elementos dos recursos do currículo e dos recursos dos professores. 2017. 163f. Tese (Doutorado em Educação Matemática) - Faculdade de Ciências Exatas e Tecnologia. Pontifícia Universidade Católica de São Paulo. São Paulo, 2017.

SANTANA, T. S. A recontextualização pedagógica de materiais curriculares educativos por futuros professores de matemática non estágio de regência. 2015. 111f. Tese (Doutorado em Ensino, Filosofia e História da Ciência) - Programa de Pós-Graduação em Ensino, Filosofia e História da Ciência. Universidade Federal da Bahia. Universidade Estadual de Feira de Santana. Salvador, 2015.

SILVA, M. S. A recontextualização de materiais curriculares educativos sobre modelagem matemática por professores nas práticas pedagógicas. 2013. 144f. Dissertação (Mestrado em Ensino, Filosofia e História da Ciência) - Programa de Pós-

Revista de investigação e divulgação em Educação Matemática, Juiz de Fora, v. 3, n. 2, p. 5-21, jul./dez. 2019. 
Graduação em Ensino, Filosofia e História da Ciência. Universidade Federal da Bahia. Universidade Estadual de Feira de Santana. Salvador, 2013.

SOUZA, J. V. B. Professores de matemática e materiais curriculares educativos: participação e oportunidades de aprendizagens. 2015. 109f. Tese (Doutorado em Ensino, Filosofia e História da Ciência) - Programa de Pós-Graduação em Ensino, Filosofia e História da Ciência. Universidade Federal da Bahia. Universidade Estadual de Feira de Santana. Salvador, 2015. 